Article

\title{
Knowledge and Attitude among Nyamagana Community Members towards Mental illness, Tanzania.
}

\author{
Samson Peter Mvandal ${ }^{1 *}$, Rosemary Mushi ${ }^{2}$ and Kudra Mponzi ${ }^{3,}$ \\ 1Department of Public Health and Tropical Medicine; samsonpim@gmail.com \\ 2Department of Public Health PIM Foundation, Tanzania; roseynamushi@gmail.com \\ 3Department of Community medicine; kudramponzi83@gmail.com \\ *Correspondence Email: samsonpim@gmail.com
}

\begin{abstract}
Background: Knowledge and attitude towards mental illness play major role in the recognition, management, sociocultural factors and health seeking behavior among those with mental disorders. The study aim was to determine the knowledge and attitude among Nyamagana community members towards mental illness, Tanzania.
\end{abstract}

Methodology: A descriptive cross-sectional quantitative study involving 384 participants from sample population aged 18 years and above who were mentally health and semistructured questionnaires was used to collect data.

Results: The findings from this study showed about $110(28.8 \%)$ respondents have good knowledge toward mental illness, about 292(76\%) have negative attitude towards mentally ill people, 92(24\%) respondents have positive attitude toward people who are mentally ill. More over about $318(82.9 \%)$ respondents agreed that care and support of family and friends, could help people with mental illness to get rehabilitation while 66(17.1\%) respondents disagreed on the care and support of the family and friends could help mentally ill people to get rehabilitation.

Conclusion: The findings show most have poor knowledge and negative attitudes towards people with mental illness and may impair their social reintegration in the community. There's need to develop strategies to enlighten the public regarding nature of mental illness so as to foster acceptance of people with mental illness by the community members.

Keywords: Attitude, Community, Knowledge, Mental health, Mental illness 


\section{INTRODUCTION}

Mental health knowledge as the knowledge and belief about mental disorder which aid their recognition management or prevention. This includes the ability to recognize specific disorders, knowing how to seek mental health information, knowledge of risk factors and its causes, knowledge of self-treatment and professional help ${ }^{[1]}$. Mental illness can be experienced over many years; the type, intensity and duration of symptoms vary from person to person. The most common forms of mental illness are anxiety disorders and depressive disorders. ${ }^{[2]}$

About 450 million people mental illness or behavioral disorders are receiving treatment and community have poor knowledge and negative attitude towards mental illness result in its avoidance, exclusion from daily activities, inappropriate mental care for them and in worst case, exploitation and discrimination (World Health Report 2001) ${ }^{[2]}$. Globally, knowledge and attitude concern mental illness are quiet poor because communities may be unaware that effective treatment is available for mental illness, the ignorance and stigma prevent such persons from seeking appropriate help, also it believed that people with mental illness must be isolated from others, they had no any opportunity in community and not allowed to integrate in social activities ${ }^{[3]}$.

According to Arkar H. Eker 2008 in Western Arab the study showed that most of people have poor knowledge concern mental illness towards etiologies and presenting features, also people have negative attitude on mental illness that was incurable or self-inflicted, leading people not being referred for appropriate mental health care ${ }^{[4]}$. Suhaila Ghuloum 2006 in his study said that, about $48.3 \%$ of Western people believed mental illness is a result of punishment from God ${ }^{[5]}, 40 \%$ believes that substance abuse like alcohol or drugs could result in mental illness ${ }^{[3,6]}$.

Study done in New York 2008 showed that due to poor knowledge, mental illness like epilepsies is still high stigmatized, particular because it often considered as infectious, which leads to social isolation (Boer et al., 2008). The burden of epilepsy may be due to the physical hazards of epilepsy resulting from the unpredictability of seizures, the social exclusion as a result of negative attitudes of others toward people with epilepsy and the stigma, as children with epilepsy may be banned from school, adults may be barred from marriage and 
employment is often denied, even when seizures would not render the work unsuitable or unsafe $^{[7]}$

In Ethiopia where poverty, war, famine, displacement and homelessness are common, mental health is also becoming a major public health problem. According to study conducted in Agaro Ethiopia 2003 showed that $15 \%$ of participants recognized major depression as mental health problem and $74 \%$ of respondent recognized a person with Schizophrenia is suffering from mental health problems ${ }^{[8]}$. Public had negative attitude towards educational opportunity for a people with epilepsy whereby illiterate person had negative attitude than literate towards living with person with epilepsy and schizophrenia in the same house ${ }^{[9]}$

Community attitudes influence the help seeking behavior of mental health sufferers. Ignorance about advances in the diagnosis and management of MI, the availability of effective treatment, and the fear of stigmatization may prevent people with mental disorders from seeking professional help. Moreover, the community attitude and perception towards behavior disorder or mental illness play a major role in successful treatments and social reintegration of the mentally ill persons. Also, these help in the determination of help seeking behavior and adherence to drug treatment ${ }^{[10]}$. People's beliefs towards MI should not only be known, but the purpose of their beliefs should be understood; such attitudes and beliefs about MI can only be studied within a cultural context ${ }^{[11,12,13]}$.

Study conducted in Dodoma, Tanzania showed that $85.9 \%$ had poor knowledge about mental illness, $51 \%$ could not identify any type of illness, $58.9 \%$ connoted negative attitude towards persons with mentally illness ${ }^{[14]}$. Study done in Dar es Salaam showed that $61 \%$ of participant responded that mental ill people cannot perform regular jobs, had no friends, and were dangerous. Respondent $79.65 \%$ had negative attitude towards people with mental illness as they stated that they have no right to find a job, have friends and be intergraded into society ${ }^{[1]}$. The result conclude that the Kinondoni community members have less knowledge and negative attitude towards mental illness and no studies were done in Mwanza town concerning this topic. Therefore, this study has great value on assessing the knowledge of the community towards mental illness in Nyamagana district, Tanzania.

\section{MATERIALS AND METHODS}


The research design was a descriptive cross-sectional study a quantitative method.

\section{Study Area}

The study was conducted in Nyamagana district located at Mwanza region, Tanzania.

\section{Inclusion Criteria}

This study included mentally health people aged 18 years and above, both males and females residing in Nyamagana District, Tanzania.

\section{Exclusion Criteria}

Mentally healthy people aged below 18 years, refusal to participate, seriously ill persons, mentally sick and failure to speak Swahili or English were not included, and mentally healthy people who were non-residents of Nyamagana district.

\section{Study design and Sampling}

The present study was designed to assess the knowledge and attitude of Nyamagana community members regarding mental illness. The study was conducted in the community setting of Nyamagana district, Tanzania. In this study target population size of 384 mentally health people aged $\geq 18$ years were selected.

\section{Methods of data collections}

Data was collected from the participants through self-structured administered questionnaire. The questionnaire was designed which contains information on various study variables, items on knowledge include common mental illness, attitude towards meaning, causation, signs and symptoms, management, prevention and rehabilitation of mental illness.

\section{Statistical analysis}

The data analysis was planned to include descriptive and inferential statistics; data were entered into Microsoft excel and then exported to Statistical Package for Social Sciences software (SPSS version 20.0) for further analysis and presented on the percentages and table. 
The analysis of strength of relationships between categorical variables were conducted using the Chi-square test. A p-value of $<0.05$ was considered to be statistically significant.

\section{Ethical consideration}

The ethical clearance for conduction of this study was approved by the Joint Catholic of Health and Allied Sciences and Bugando Medical Centre Research Ethics and Review Committee (CREC) with registration number 1369/2019. Permission to conduct the research in Nyamagana district was obtained from District Medical Officer (DMO). Written informed consent was obtained from each study participant before the administration of questionnaires. All subjects gave their informed consent for inclusion before they participated in the study. For ethical reasons, the participants were free for refusing to fill the questionnaire. No participant name was filled on the forms rather than code numbers to ensure confidentiality.

\section{RESULTS}

\subsection{Socio-demographic characteristics}

A total of 384 respondents were included in the analysis, after removing forms with major errors and those which were grossly incomplete. Gender distribution of the respondents was nearly equal; 200 (52.08\%) were male and 184 (47.92\%) were female, among the respondents $310(80.82 \%)$ were Christian, 68(17.8\%) were Islam and 5(1.4\%) were pagan, about 249.9 $(65.08 \%)$ who responded to questionnaire ranged age 18-29 years, $107.5(27.99 \%)$ ranged age 30-49 years, $26.3(6.8 \%)$ ranged age 50-69 years. (Table 1$)$

In this study most of the respondents 208 (54.1\%) were from Bugarika, 50 (13.0\%), were from Igogo, 34 (8.9\%) were from Mahina, 13 (3.4\%) were from Mkuyuni, 58 (15.1\%) were from Pamba and were from Buhongwa. (Table 2 below) 
Table 1. Sociodemographic characteristics

\begin{tabular}{|c|c|c|}
\hline Category & No. & $\%$ \\
\hline \multicolumn{3}{|l|}{ Gender } \\
\hline Male & 200 & 52.08 \\
\hline Female & 184 & 47.92 \\
\hline \multicolumn{3}{|l|}{ Age(years) } \\
\hline $18-29$ & 250 & 65.10 \\
\hline $30-49$ & 108 & 28.13 \\
\hline $50-69$ & 26 & 6.77 \\
\hline \multicolumn{3}{|l|}{ Religion } \\
\hline Christian & 310 & 80.82 \\
\hline Islamic & 68 & 17.80 \\
\hline Pagan & 5 & 1.40 \\
\hline \multicolumn{3}{|c|}{ Marital status } \\
\hline Single & 234 & 61.0 \\
\hline Married & 116 & 30.20 \\
\hline Divorced & 13 & 3.40 \\
\hline Widow & 8 & 2.10 \\
\hline Separated & 13 & 3.40 \\
\hline \multicolumn{3}{|c|}{ Education level } \\
\hline University & 113 & 29.5 \\
\hline College & 100 & 14.4 \\
\hline Secondary & 226 & 26.0 \\
\hline Primary & 55 & 23.3 \\
\hline Informal & 68 & 6.8 \\
\hline
\end{tabular}


Table 2: Address

\begin{tabular}{lcccc}
\hline \multicolumn{1}{c}{ Area } & Frequency & Percent & Valid \% & Cumulative \% \\
\hline Bugarika & 208 & 54.1 & 54.1 & 54.1 \\
Buhongwa & 21 & 5.5 & 5.5 & 100.0 \\
Igogo & 50 & 13.0 & 13.0 & 67.1 \\
Mahina & 34 & 8.9 & 8.9 & 76.0 \\
Mkuyuni & 13 & 3.4 & 3.4 & 79.5 \\
Pamba & 58 & 15.1 & 15.1 & 94.5 \\
\hline
\end{tabular}

\subsection{Community Knowledge towards mental illness}

About 110 (28.8\%) respondents had knowledge that people with mental illness should be treated equally like other people by being involved in different activities in the community and also should be treated at hospital, while 171 (44.5\%) respondents agreed that people with mental illness should be treated at hospital level only because they are dangerous in the community and should not be involved in different activities in the community and 103 (26.7\%) respondents they don't know how to deal with people having mental illness. About $318(82.9 \%)$ participants agreed that the care and support of family and friends, could help people with mental illness to get rehabilitation like involving mental illness people in different activities like farming, gardening, community meeting, while $66(17.1 \%)$ participants they believe that the care and support of family and friends could not help people with mental illness to get rehabilitation (Table 3)

Table 3: Support of family and community

\begin{tabular}{lcccc}
\hline & Frequency & Percent & Valid \% & Cumulative \% \\
\hline Yes & 318 & 82.9 & 82.9 & 82.9 \\
No & 66 & 17.1 & 17.1 & 100.0 \\
Total & 384 & 100.0 & 100.0 & \\
\hline
\end{tabular}

Through comparing people with mental disorder and their level of Intelligence Quotient, 42 (11\%) respondents said that people with mental illness have great level of IQ, $192(50 \%)$ participants said that people with mental illness have moderate level of IQ and $150(39 \%)$ people said that people with mental illness have little level of IQ. Regarding who will acquire 
mental illness, $87 \%$ said that it is possible for everyone to get a mental illness, $8.2 \%$ said that it is impossible for everyone to get a mental illness, while $14.8 \%$ said that they don't know if everyone can get mental Illness. (see table 4)

Table 4: Everyone can get Mental illness

\begin{tabular}{ccccc}
\hline & Frequency & Percent & Valid \% & Cumulative \% \\
\hline Yes & 334 & 87.0 & 87.0 & 87.0 \\
No & 32 & 8.2 & 8.2 & 95.2 \\
I don't know & 18 & 4.8 & 4.8 & 100.0 \\
\hline
\end{tabular}

\section{Community knowledge about causes of mental illness}

Regarding the causes of mental disorder, they have, 181 (47.3\%) said that mental illness, can be caused by supernatural power, 134 (34.9\%) said that mental illness can be due to God's punishment after wrongs doing, while 69 (17.8\%) said that mental illness can be caused by biological factors, psychological factors, physio-social factors. See Figure 1

\section{Figure 1: Community knowledge regarding causes of mental illness}

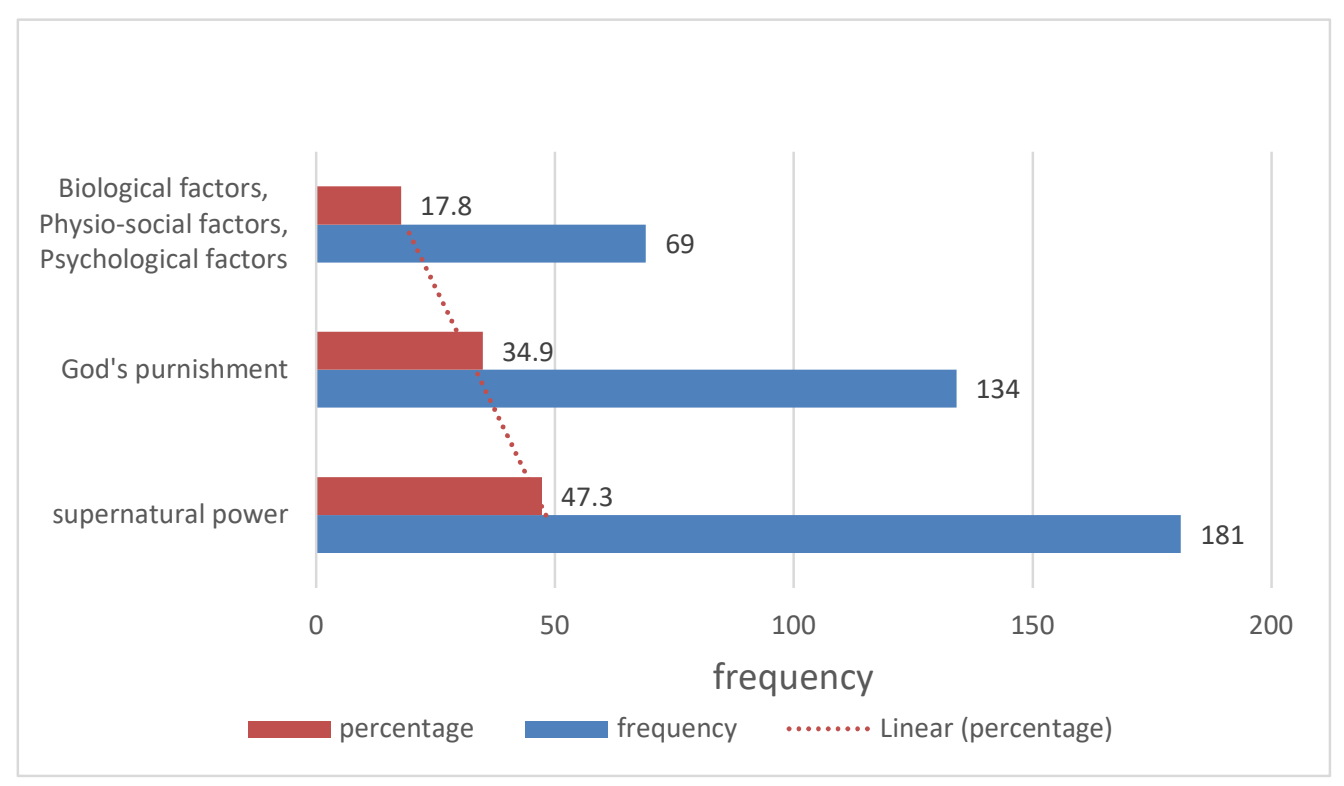

\section{Community attitude towards mental illness}


About 292(76\%) people said that people who are suffering from mental illness couldn't have many friends, while 92 (24\%) people said that people who are suffering from mental illness can have many friends. When asked if mental ill patient can have family, about $48.6 \%$ people said that it is appropriate for a person with mental illness to get married and should have children, while $51.4 \%$ people said that it is inappropriate for a person with mental illness to get married and should not have children because they cannot treat well their children due to their mentally illness condition (Table 5)

Table 5: Community attitude towards mental illness

\begin{tabular}{|c|c|c|}
\hline & Responses & $\begin{array}{c}\text { Participants } \\
\text { N }(\%)\end{array}$ \\
\hline \multirow{2}{*}{ Person with mental illness can have friend? } & Yes & $92(24.0 \%)$ \\
\hline & No & $292(76.0 \%)$ \\
\hline \multirow{3}{*}{$\begin{array}{l}\text { Best way to help those with a mental illness to } \\
\text { recover is to let them stay in the community } \\
\text { and live a normal life without discrimination or } \\
\text { segregation? }\end{array}$} & True & $108(28.1 \%)$ \\
\hline & Not true & $258(67.1 \%)$ \\
\hline & $\begin{array}{l}\text { I don't } \\
\text { know }\end{array}$ & $18(4.8 \%)$ \\
\hline \multirow{2}{*}{$\begin{array}{l}\text { People with mental illness are they have other } \\
\text { future plans in life like business, farming? }\end{array}$} & Yes & $153(39.7 \%)$ \\
\hline & No & $231(60.3 \%)$ \\
\hline \multirow[b]{2}{*}{ Mental ill patient having Family? } & Yes & $187(48.6 \%)$ \\
\hline & No & $197(51.4 \%)$ \\
\hline \multirow{2}{*}{$\begin{array}{l}\text { People with MI can Involve in other activities } \\
\text { in the community? }\end{array}$} & Yes & $153(39.7 \%)$ \\
\hline & No & $231(60.3 \%)$ \\
\hline
\end{tabular}

\section{DISCUSSION}

Findings from the study therefore regarded as window that provide glimpse into current knowledge and attitude based on the mental illness within the Nyamagana community.

It revealed that a large proportion were unaware of the issue related to mental illness. And among the participants $28.8 \%$ had good knowledge that people with mental Illness should be treated equally like other people by being involved in different activities in the community and also should be treated at hospital too, while $44.5 \%$ had fair knowledge and said that people with mental Illness should be treated at hospital level only because they are dangerous in the community and should not be involved in different activities in the community and $26.7 \%$ had poor knowledge and they said they don't know how to deal with 
people having mental Illness, and this seems somewhat comparable with the study done in Australia in $1995^{[15]}$ and study done in Uganda $2009^{[16]}$.

More over about $82.9 \%$ participants agreed that provision of care and support from family and friends, could help people with mental illness to get rehabilitation and involving them in different activities like farming, gardening, community meeting, while $17.1 \%$ people said that the care and support of family and friends could not help people with mental illness to get rehabilitation and this seems similar to study done at Zaire ${ }^{[17,18]}$

From this study data it shows that most of community members about $47.3 \%$ believed that being mentally ill is the causal effect of supernatural power, $34.9 \%$ said that mental illness can be due to God's punishment after wrongs doing, while $17.8 \%$ said that mental Illness can be caused by biological factors, psychological factors, physio-social factors. ${ }^{[19]}$ This show great burden of being knowledgeable enough on issues related to mental health. ${ }^{[20,}$ ${ }^{21]}$. The topic of mental illness itself evokes a feeling of fear, embarrassment or even disgust fostering negative attitudes towards mental illness and mentally ill people ${ }^{[22]}$.

Mental health literacy of the general public is essential for the effective promotion of society's mental health. As a common finding with the studies in Western countries, only small percentages of the Japanese and Taiwanese respondents were able to make a correct identification. A further common finding was, significantly stronger stigma perception was shown in the Japanese respondents than in the Taiwanese, which may be attributable to the high institutionalization rate in $\operatorname{Japan}^{[11,23,24]}$.

In the study shows that $76 \%$ people disagreed that people who are suffering from mental illness cannot have many friends and being isolated from their loved one, while $24 \%$ people said that people who are suffering from mental illness can have many friends and lived with their beloved one, this seems to be similar with the Study done in South Africa on stigmatization, the community have shown that people with mental illness have decided to stop taking treatment, isolated themselves from loved ones, or have given up on the things they wanted to do, because of discrimination, $40 \%$ of people with mental illness in South Africa have said that they didn't socialize, because negative stereotypes kept them isolated [25, 26]. 


\section{CONCLUSIONS}

The findings of present study reveal that most of community were having poor knowledge and negative attitudes toward mentally ill person are widespread as on its etiology and how we deal with them by providing care and management, these seem to be major reasons/factors that leads mental ill people being isolated and seem to be dangerous to them and were not involved in different activities in community and this may impair their social reintegration in the community.

\section{RECOMENDATIONS}

There is an urgent need to develop strategies to develop strategies to enlighten the public awareness regarding nature of mental illness to foster acceptance of people with mental illness by the community members. In addition to this, anti-stigma campaigns aiming to develop a healthy attitude to mental illness and evidence-based mental health educational programs insisting the importance of early treatment seeking and family participation in caring for the mental ill need to be implemented; and through these burden regarding mental illness in Tanzania will be reduce.

\section{FUNDING}

This research received no external funding

\section{CONFLICTS OF INTEREST.}

The author declares no conflict of Interests

\section{ACKNOWLEDGEMENTS.}

The authors acknowledge the PIM foundation for giving us support with various research materials including questionnaires. Joel Seme (Muhimbili university), Hugoline Ngeni, The Nyamagana District Medical Officer, Nyamagana community members for granting us the permission to conduct our survey and giving us full support needed to complete our study successfully.

\section{REFERENCES}

1. Chikomo J.G. Knowledge and Attitudes of the Kinondoni Community. Stellenbosch Univ Stellenbosch. 2011;(March):1-132.

2. Organization WH. Mental health, new understanding, new hope. World Heal Rep 2001. 2001. World Health Organization 2001.

3. Corrigan PW PD. Lessons from social psychology on discrediting psychiatric stigma. 
Am Psychol. 1999;54(9):765.

4. Al-Krenawi A, Graham JR. Culturally Sensitive Social Work Practice with Arab Clients in Mental Health Settings. Health Soc Work. 2000;25(1)(February)::9-22.

5. Ghuloum S. Psychiatry in Quatar. Bull Board Int Aff R Coll Psychiatr. 574:16-18.

6. Kabir M, Iliyasu Z, Abubakar IS, Aliyu MH. Perception and beliefs about mental illness among adults in Karfi village, northern Nigeria. BMC Int Health Hum Rights. 2004. doi:10.1186/1472-698X-4-1

7. Boer HM De, Mula M, Sander JW. The global burden and stigma of epilepsy. 2008;12:540-546. doi:10.1016/j.yebeh.2007.12.019

8. Deribew A, Tamirat YS. Original article How are mental health problems perceived by a community in Agaro town? Ethiop J Heal Dev. 2005;19(2):153-159.

9. Dixon LB, Dickerson F, Bellack AS, et al. The 2009 Schizophrenia PORT Psychosocial Treatment Recommendations and Summary Statements. 2010;36(1):48-70. doi:10.1093/schbul/sbp115

10. Hugo CJ, Boshoff DEL, Traut A, Stein NZDJ. Community attitudes toward and knowledge of mental illness in South Africa. 2020;(2003):715-719. doi:10.1007/s00127003-0695-3

11. Jorm AF, Jorm AF. Mental Health Literacy: Empowering the Community to Take Action for Better Mental Health. 2011. doi:10.1037/a0025957

12. Gureje OYE, Lasebikan VO, Ephraim-oluwanuga O, Oluwanuga EA-, Olley BO, Kola L. Community study of knowledge of and attitude to mental illness in Nigeria. 2002:436-441.

13. Davies S. Mental disorders in the developing world. 1994;308:23-24.

14. Magreth B, Mndeme E, Mwakagile. DSM, Mwansisya TE. Community Knowledge, Attitudes and Perception towards Mental Illness in Dodoma Municipality, Tanzania. ARC J Public Heal Community Med. 2016. doi:10.20431/2456-0596.0103002

15. Sakellari E. Exploring The Impact of Mental Health Education on Adolescent' Perceptions about Mental Health and Mental Illness. Improving Community Health.; 2014.

16. Ssebunnya J, Kigozi F, Lund C, Kizza D, Okello E. Stakeholder perceptions of mental health stigma and poverty in Uganda. BMC Int Heal Hum Rights. 2009;9(1):5.

17. Doris FA, Sylvia AA. Perceptions and Beliefs about Mental Illness ( Schizophrenia ) among Adults in Zaare Community. 2015;5(9):150-159.

18. Linton S. Claiming disability: Knowledge and identity: NYU Press: 1998.

19. Al-Adawi S, Dorvlo ASS, Al-Ismaily SS, et al. Perception of and attitude towards mental illness in Oman. Int $J$ Soc Psychiatry. 2002;48(4):305-317. doi:10.1177/002076402128783334 
20. Magliano L, Fiorillo A, De Rosa C, Malangone C, Maj M, Group NMHPW. Family burden in long-term diseases: a comparative study in schizophrenia vs. physical disorders. Soc Sci Med. 2005;61(2):313-322.

21. Avasthi A. Preserve and strengthen family to promote mental health. Indian J Psychiatry. 2010;52(2):113.

22. Arthur Kleinman. Rethinking Psychiatry: from cultural category to personal experience. New York. Free Press. 1991.

23. Ukawana K. Guideline for Conducting a Knowledge, Attitude and Practice (KAP) Study, ,. 2004;Vol. IV, N(Jan-Mar):7-9.

24. More VP, Jadhav PB, Puranik R, Shinde VS. Study of Knowledge and Attitude Concerning Mental Illness in Adults. Int J Heal Sci Res. 2012;2(August):1-6.

25. Jacoby A, Snape D, Baker G. Epilepsy and social identity: the stigma of a chronic neurological disorder. Lancet Neurol. 2005;4(3):171:8.

26. Tzouvara V, Papadopoulos C. Public stigma towards mental illness in the Greek culture. J Psychiatr Ment Health Nurs. 2014. doi:10.1111/jpm.12146 